\title{
LEITURA DE IMAGENS NO JORNAL - HUMOR GRÁFICO, MÍDIA E EDUCAÇÃO
}

Reading images in newspaper - graphic humour, media and education

Ana Rosa Vidigal Dolabella ${ }^{1}$

\section{Resumo}

O objetivo deste artigo é relatar e discutir uma experiência de educação para a mídia, a partir da leitura do Humor Gráfico no jornal impresso, como proposta de formação de professores através da extensão universitária do curso de jornalismo, baseada na perspectiva do letramento e no campo dos estudos da análise de discursos.

Palavras-chaves: Letramento midiático; Humor gráfico; Jornal impresso.

\section{Abstract}

The objective of this article is to describe and to discuss an educational experience for the media as from the reading of cartoons in newspapers, as a proposal for teachers

development through the university extention of the journalism course, based on literacy perspectives and discourse analysis.

Keywords: Media literacy; Graphic humour; Newspaper.

\section{Introdução}

A proposta deste texto é apresentar algumas das ações do Projeto de Extensão "Jornal, Leitura e Escola", desenvolvido no ano letivo de 2006 e de 2007 no curso de Jornalismo do Centro Universitário de Belo Horizonte (Uni-BH) em parceria com escolas públicas estaduais de Minas Gerais e discuti-las à luz de teorias da Lingüística Textual e da Análise de Discursos, no que diz respeito ao que constituiria uma proposta de educação para a mídia ou "letramento midiático", isto é, a formação de um bom leitor de mídia nas escolas

Formada em Comunicação Social; Doutoranda em Lingüística (Pontifícia Universidade Católica de Minas Gerais - PUC Minas); Mestre em Letras/Análise do Discurso (Universidade Federal de Minas Gerais - UFMG); professora nos cursos de Jornalismo, Pedagogia e Psicopedagogia e coordenadora de projetos de extensão e pesquisa no Centro Universitário de Belo Horizonte/Uni-BH. e-mail: anarosavidigal@gmail.com 
de educação básica. O foco dessa discussão é a leitura de imagens, principalmente, que compõem a charge e o cartum, gêneros discursivos do humor gráfico em jornais impressos.

Em um primeiro momento, apresentamos o Projeto "Jornal, Leitura e Escola" e delimitamos as ações realizadas em torno de um de seus aspectos temáticos que é o Humor Gráfico e a leitura de charges e cartuns no jornal impresso. Em seguida, trataremos da abordagem da Lingüística Textual e da Análise de Discursos no que se refere aos elementos de análise e interpretação da leitura de imagens de humor gráfico. Posteriormente, falaremos da perspectiva da leitura da mídia como formadora da educação do olhar e da escuta e da construção da formação de professores como agentes de letramento midiático.

\section{Jornal, leitura e escola}

"Ler o jornal" significa, na proposta de uma educação para a mídia que fundamenta o Projeto de Extensão "Jornal, Leitura e Escola” problematizálo considerando: o conflito entre público (função social do jornalismo) e privado (empresarial; condição mercantilista do jornalismo); a construção do real (objeto-de-mundo x objeto-de-discurso) e representação da complexidade de uma sociedade não-polarizada (processos de referenciação do acontecimento-referente e explicitação/implicitação de elementos desse processo no texto da notícia) condições de produção do discurso jornalístico. Para tanto, o Projeto foi realizado pela primeira vez no ano letivo de 2006 no curso de Jornalismo do Uni$\mathrm{BH}$, com a participação de dois alunos bolsistas e dois alunos voluntários de diferentes períodos do curso de jornalismo $\left(3^{\circ}\right.$ ao $\left.7^{\circ}\right)$ selecionados através de edital. O projeto propõe a realização de intervenções na comunidade escolar no que diz respeito a ações educativas para leitura crítica a partir da mídia impressa e a abordagem do texto noticioso em sala de aula de escolas de Educação Básica.

O objetivo principal do projeto é intervir nas práticas educativas da comunidade escolar em geral com vistas a potencializar o uso do jornal nas aulas de leitura e produção de textos, a partir do conhecimento da especificidade da linguagem e do texto jornalístico noticioso de imprensa escrita na perspectiva do letramento. Para isso, buscamos valorizar a prática de leitura e abordagem do texto noticioso a partir do posicionamento crítico e discussão de diferentes pontos de vista/ jornal como "arquilocutor" (MOUILLAUD, 1997) e incentivar a compreensão da realidade representada pela linguagem jornalística como multifacetada e, portanto, polifônica e dialógica (BAKHTIN, 2000). Na perspectiva das condições de produção e recepção do conteúdo midiático propriamente dito, buscamos incentivar uma leitura crítica pautada na situaçãocontrato de comunicação midiática proposta na Semiolingüística (CHARAUDEAU, 2005, 2006).

Sua importância se baseia na proposta de extensão universitária, o que expõe o vínculo com o projeto pedagógico do curso de graduação ao qual está vinculado e que apresenta como beneficiários diretos do projeto os próprios alunos do curso. Esses alunos percebem nas atividades desenvolvidas novas formas de lidar com o conhecimento construído em sala de aula, e nesse caso, compreendem mais diretamente questões pertinentes à ética jornalística. Além dos alunos, são beneficiadas as escolas - corpos discente e docente - que participaram conosco das discussões propostas. Dessa maneira, acreditamos promover, através do projeto, a ação educativa no tratamento de mídias impressas de grande circulação nacional e de referência no universo das práticas escolares da comunidade em geral.

Como metodologia de implantação, execução e avaliação do projeto, ressaltamos: a preparação dos alunos bolsistas na discussão, planejamento e organização das intervenções na comunidade escolar; o desenvolvimento de estratégias de ação, aproximação, argumentação e ilustração das condições de produção e recepção da linguagem jornalística e seu uso como texto escolarizado; a implantação de um programa de intervenção junto a alunos e professores da comunidade escolar escolhida (observando: as especificidades da linguagem jornalística; o texto noticioso da imprensa escrita de referência; a estrutura da notícia; processo de interação verbal; a articulação do texto noticioso no jornal com elementos gráficos, foto, legenda, contextualização, etc).

Foram realizadas visitas semanais nas escolas em questão e o registro de avaliação de forma contínua, dinâmica e processual, na coleta de dados e informações dos participantes da comunidade escolar, alunos bolsistas e voluntários, baseada na ação/reflexão/ação aprimorada.

Também realizamos reuniões semanais na Casa de Pesquisa e Extensão do Uni-BH com duração 
de duas horas aproximadamente para discussão dos processos de avaliação e o estudo de textos previamente escolhidos sobre os temas em questão.

Outras ações para a formação dos próprios alunos bolsistas e voluntários foram implementadas no Projeto. Uma visita ao jornal Estado de Minas, que permitiu o acompanhamento de turmas de educação básica e da proposta de educação para a mídia que é realizada pelo mesmo jornal. Os estudantes também tiveram a oportunidade de entrevistar jornalistas do Estado de Minas em seu local de trabalho, acompanhando suas atividades de elaboração de pauta e produção de textos - para o jornal impresso e o portal na internet.

Ainda na perspectiva da formação dos estudantes para a atuação em escolas públicas, o grupo do Projeto Jornal, Leitura e Escola participou da Semana de Pedagogia do Uni-BH (maio/2006) com o objetivo de ministrar oficinas para o público pedagogo, experimentar as atividades elaboradas por nós e avaliar os primeiros resultados anteriormente à ida às escolas parceiras do Projeto.

Finalmente, outra vivência importante do grupo do Projeto de Extensão Jornal, Leitura e Escola foi a realização da Oficina Leitura de Charge em Jornais, que aconteceu no $7^{\circ}$. Salão do Livro de Belo Horizonte (agosto/2006) em interface com o Projeto de Pesquisa de Iniciação Científica Oralidade e Formação de Professores, realizado em 2006 no curso de Pedaogogia do Centro Universitário de Belo Horizonte/Uni-BH. Nessa oficina, participaram estudantes do curso de Jornalismo e do curso de Pedagogia (Uni-BH) em parceria com a Editora RHJ que, na época, lançava o livro de cartuns $A$ linha de Mário Vale, de autoria de Mário Vale, cartunista publica no jornal Hoje em Dia. A oficina foi aberta à comunidade em geral, contou com a participação de um público diversificado - de cartunistas a professores de educação básica, e visitantes da feira que se inscreveram no local.

\section{Leitura de imagens: a charge e o cartum - comentário, referenciação e inferenciação}

Das ações educativas de leitura de mídia impressa, previstas no Projeto "Jornal, Leitura e Escola", focalizamos o trabalho com charges e cartuns nos jornais neste artigo. Isso se dá pela variedade de possibilidades de leitura que esse tipo de gênero discursivo apresenta (no nosso foco particular, que é a educação para a mídia): em seu conteúdo semântico, a retomada da notícia através do lúdico e da crítica, o comentário; em sua forma, a síntese da mensagem de alguns centímetros quadrados; em sua proposta, que nos convida à reflexão pelo riso irônico ou pela poesia dos traços. E talvez, por isso, charges e cartuns, modalidades discursivas do Humor Gráfico, conquistam cada vez mais importância em jornais impressos de referência no Brasil e no exterior, publicadas não somente nas editorias de política e opinião, mas também na primeira página, disputando o espaço com manchetes do dia. ${ }^{2}$

De acordo com estudos realizados pelo grupo do Projeto de Extensão - baseados em autores como Bergson (1980), Castro (1994) e Romualdo (2000), e na opinião de chargistas e cartunistas como Santos (2006), Vale (2006) e Jaguar (em entrevista a Colombo, 2007) - e por reflexões desenvolvidas pelo próprio grupo (DINIZ et al., 2006; DOLABELLA, 2006a), acreditamos que a charge e o cartum constituem um gênero textual icônico-verbal, ou seja, usam imagem e palavras, que são interdependentes na produção de sentido. Isso quer dizer que, para interpretar uma charge, ou um cartum, o leitor precisa de ferramentas como leitura de imagens, conexão entre textos verbal e não-verbal e contextualização. Isso não significa que basta o que está grafado no papel, seja imagem seja palavra, para entender esse tipo de texto. O leitor precisa ainda da referência sócio-histórica para a constituição do sentido.

A interpretação da charge ou do cartum envolve a complexidade do processo enunciativodiscursivo, ou seja, as condições de produção e percepção do humor gráfico de acordo com uma determinada situação de comunicação. Ainda que se tome charge por cartum e vice-versa, na literatura em geral, e ainda que se chame o autor de chargista ou cartunista, de forma generalizada, vamos fazer uma distinção neste artigo entre essas duas modalidades de humor gráfico.

Como traço característico, a charge tem a pretensão de influenciar a opinião dos leitores a respeito de algum ponto de vista adotado pelo veículo/empresa de comunicação onde é publicada.

2 A esse respeito, vejam-se os exemplos das primeiras páginas no Jornal O Globo (RJ/Brasil) e no Le Monde (França), particularmente as edições do dia 8/11/2006. 
Isso é verificado na medida em que a charge ocupa espaços privilegiados nos jornais impressos, por exemplo, retomando alguma notícia de primeira página ou editoriais. Mas a charge não substitui o acompanhamento das notícias, porque charge não é informativa. A charge se fundamenta normalmente em uma crítica baseada em um acontecimento, ou uma série de acontecimentos, noticiado(s) pela grande imprensa, de uma determinada realidade sócio-econômica e, portanto, assume claramente uma posição política.

O cartum, por outro lado, busca um foco no cotidiano, nas questões da condição humana. É por esse motivo que o cartum é, geralmente, "universal" e atemporal, ou seja, pode ser compreendido em diferentes culturas e sociedades em diferentes épocas.

Como todo texto, há charges e cartuns de melhor qualidade do que outros. Isso porque a charge e o cartum se articulam a partir do mesmo eixo constitutivo: o que faz esse tipo de texto ter excelência ou não é a articulação entre iconicidade e linearidade (DOLABELLA, 2006b), isto é, a articulação na charge entre a imagem que fala e as palavras que calam!

E como produzimos sentido a partir do "texto" do humor gráfico? Por que produzimos um riso "adjetivado" - aliviado, irônico, incômodo - na "leitura" da charge ou do cartum? Quais as estratégias discursivas envolvidas na construção do sentido, quais as competências e habilidades requeridas nesse processo?

O cartum e a charge se baseiam nos saberes partilhados de sujeitos de um grupo social. São construídos a partir de um conhecimento prévio determinado, articulado a uma memória discursiva, em uma ampla rede de conexões para que, como falamos anteriormente, a mensagem produza o efeito desejado em um espaço físico do papel (aqui tratamos do material impresso) tão exíguo. Segundo, Riani (2002), um dos principais componentes do trabalho de humor gráfico diz respeito ao exagero, ao aumento desproporcional e intencional das formas, fatos e atitudes. "Tal "distorção" é utilizada como estratégia discursiva, possibilitando dar ênfase aquilo que se deseja dizer, ao mesmo tempo em que insere o tom humorístico, vital para a caracterização desse segmento" (RIANI, 2002).

Das várias estratégias discursivas, baseadas em Riani (2002), utilizadas no Humor Gráfico síntese, paródia, o ridículo, a ruptura, estilização, a ambigüidade/duplo sentido - destacamos neste artigo, a título de análise, a recategorização $(\mathrm{KOCH}$, 2005). Nesse sentido, consideramos a charge, especialmente, a retomada de algum fato (ou dito) relatado na imprensa em geral, um acontecimento que virou notícia.

"No discurso jornalístico, o acontecimento constitui o referente de que se fala" (RODRIGUES, 1999, p. 27). Em textos jornalísticos noticiosos, a ação ou a fala ${ }^{3}$ de alguém pode ser o próprio acontecimento de que se fala ou ainda ser parte deste acontecimento. Assim, assumimos a perspectiva de "construção construtivista da referência" $(\mathrm{KOCH}$, 2005 , p. 33), em que os interlocutores estejam comprometidos com o processo de construção do próprio real e se percebem co-construtores nesse processo.

No caso da notícia, ela se constrói na categorização do fato, no caso, do dito, da declaração ou do feito de alguém. Os elementos referenciais no texto noticioso vão recategorizando e particularizando esse objeto-de-discurso que é o fato/dito relatado (DOLABELLA, 2006b). Na charge, então, o acontecimento seria novamente recategorizado, situando-se no que chamaremos de "comentário" midiático, e não no relato, em que se situa a notícia.

Aos elementos de referenciação, tomamos igualmente os elementos de inferenciação. A partir da concepção de contexto assumida por Assis (2002), aceitamos que

Um texto é explícito quando fornece informações suficientes para que o destinatário possa identificar o quadro referencial para sua interpretação, o que leva à realidade de que nem tudo é dito/explicitado verbalmente em um texto, na medida em que as inferências, pressupostos, subentendidos e intenções - que

\footnotetext{
3 No processo de referenciação, o discurso relatado é objeto-de-discurso, que se apresenta de diferentes formas no texto noticioso: como citações (trecho transcrito na íntegra e marcado pela presença de aspas); como ilhas de aspeamento (palavras ou expressões transcritas da fala de outrem); como parafraseamento em discurso indireto ou em expressões introdutórias (como Conforme, Segundo, De acordo com...); e ainda, mesmo que menos comum, como discurso indireto livre (DOLABELLA, 1999).
} 
compõem o quadro do implícito em um texto - estão relacionados às condições cognitivas de interpretação do leitor/ouvinte e às estratégias de verbalização do produtor, num constante processo de negociação. (ASSIS, 2002, p. 20).

$\mathrm{Na}$ charge, a busca do equilíbrio entre o que referido e o que é inferido aguça ainda mais essa negociação: a charge não deve trazer elementos a mais no texto, que a tornariam redundante ou que desviariam a atenção do leitor do foco estabelecido pelo chargista. Dessa forma, produzir sentido em uma interação a partir de um texto, seja imagético ou não, ainda de acordo com Assis (2002, p. 22-23):

Não é, portanto, um aspecto vinculado à língua ou à outra modalidade, e sim resultado de um jogo coletivo. Aceitas essas idéias, é possível entender, como esclarece Koch (2005), ao discorrer sobre os procedimentos de referenciação, que, mesmo que não estejam explicitadas verbalmente, determi- nadas informações são inferidas com o apoio dos referentes estocados na memória dos interlocutores -, desde que ativados por pistas deixadas na superfície textual. Daí se entende por que se pode afirmar que um texto diz mais do que diz, ou seja, revela mais do que nele se verbaliza.

E também é possível compreender melhor o que a máxima diz uma imagem vale mais que mil palavras. Assim, nas palavras de Assis (2002, p. 26), "o produtor [humorista gráfico] deverá decidir sobre o que necessita ser explicitado textualmente e o que pode permanecer implícito, uma vez que poderá ser recuperado pelo ouvinte através de inferenciação". As idéias de explicitação e de implicitação apresentam-se na perspectiva do texto/ contexto, no nosso caso do discurso midiático impresso, e vinculam-se, no nosso ponto de vista, aos efeitos de sentido ou estratégias do discurso informativo. É o que podemos observar nos exemplos de humor gráfico a seguir.
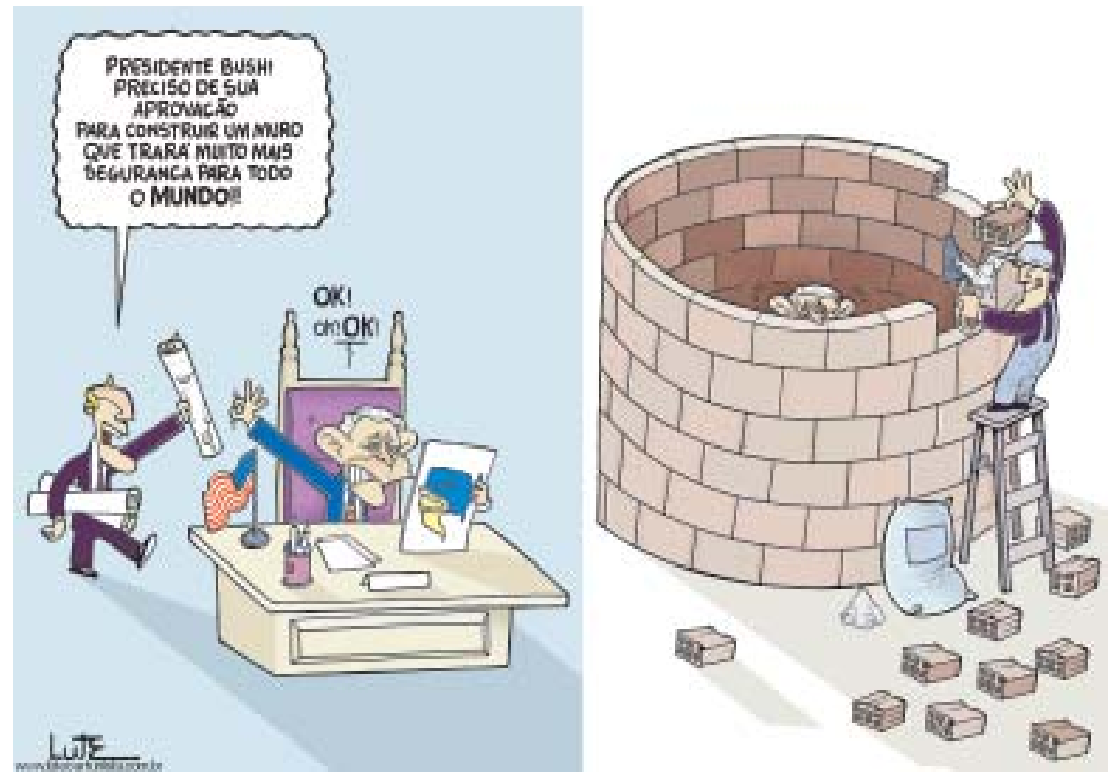

Figura 1 - Charge a Lei do Muro

$\mathrm{Na}$ charge acima ${ }^{4}$ (Figura 1), ${ }^{5}$ o chargista trata do tema ${ }^{6}$ polêmico, a "Lei do Muro", aprovada pelo senado americano e posteriormente sancionada pelo Presidente dos Estados Unidos. Nessa charge, o humorista apresenta uma seqüência narrativa em dois quadros. No primeiro quadro, a caricatura de

4 Cedida gentilmente por Lute. Lunarde Teles dos Santos, o Lute, é chargista a de opinião do jornal Hoje em Dia há mais de 10 anos. Colaborou com diversos jornais e revistas, entre eles o Jornal do Brasil, O Pasquim 21, e Veja. Participou com ilustrações, cartuns e charges em livros e exposições no Brasil e no exterior; também organizou exposições e ganhou prêmios, entre eles, o primeiro lugar no $28^{\circ}$ Salão Internacional de Humor de Piracicaba - 2001 - São Paulo.

5 Jornal Hoje em Dia.

6 A notícia foi divulgada pelo jornal Folha de S. Paulo em 5 de outubro de 2006, intitulada "Bush aprova US\$1,2 bi para construir muro na fronteira" e trata da lei orçamentária sancionada pelo Presidente dos Estados Unidos que prevê a construção de um muro de $1200 \mathrm{~km}$ na fronteira com o México, com o objetivo de reforçar a vigilância naquela região contra a imigração ilegal. 
Bush - estilizada pelas orelhas proeminentes, e reforçada pela referenciação na fala de um segundo personagem e pelo mapa dos EUA. O chargista cria uma expectativa no leitor ao apresentar esse segundo personagem, anônimo, percebido por índices inferenciais como um possível assessor do Presidente ("preciso de sua aprovação") e que traz algo novo ("um muro que trará muito mais segurança") no cenário político mundial. No segundo quadro, a ruptura lúdica peculiar à charge: o caçador vira caça - sem a necessidade de um texto linear/verbal, o texto icônico/imagético propõe sentido - a "segurança" do primeiro quadro é retomada na palavra em negrito "mundo", e passa a ser recategorizada: já diz respeito à comunidade internacional, e não, em princípio, apenas aos americanos. O muro, que por ora se faz construir, é circular, pontual, particular e pretende isolar não os estrangeiros dos americanos, mas os americanos personificados por Bush - do mundo inteiro.

Para entender a charge, como podemos notar, é preciso muito mais do que as imagens; é preciso acionar elementos de referenciação e de inferenciação, de texto e de contexto, muito vinculados à temporalidade. E não é somente isso: a leitura crítica demanda a ativação de elementos que concernem às diferentes linguagens: ética, estética, cultural, histórica, social, política. ${ }^{7}$ Isso não é diferente quanto à leitura do cartum.

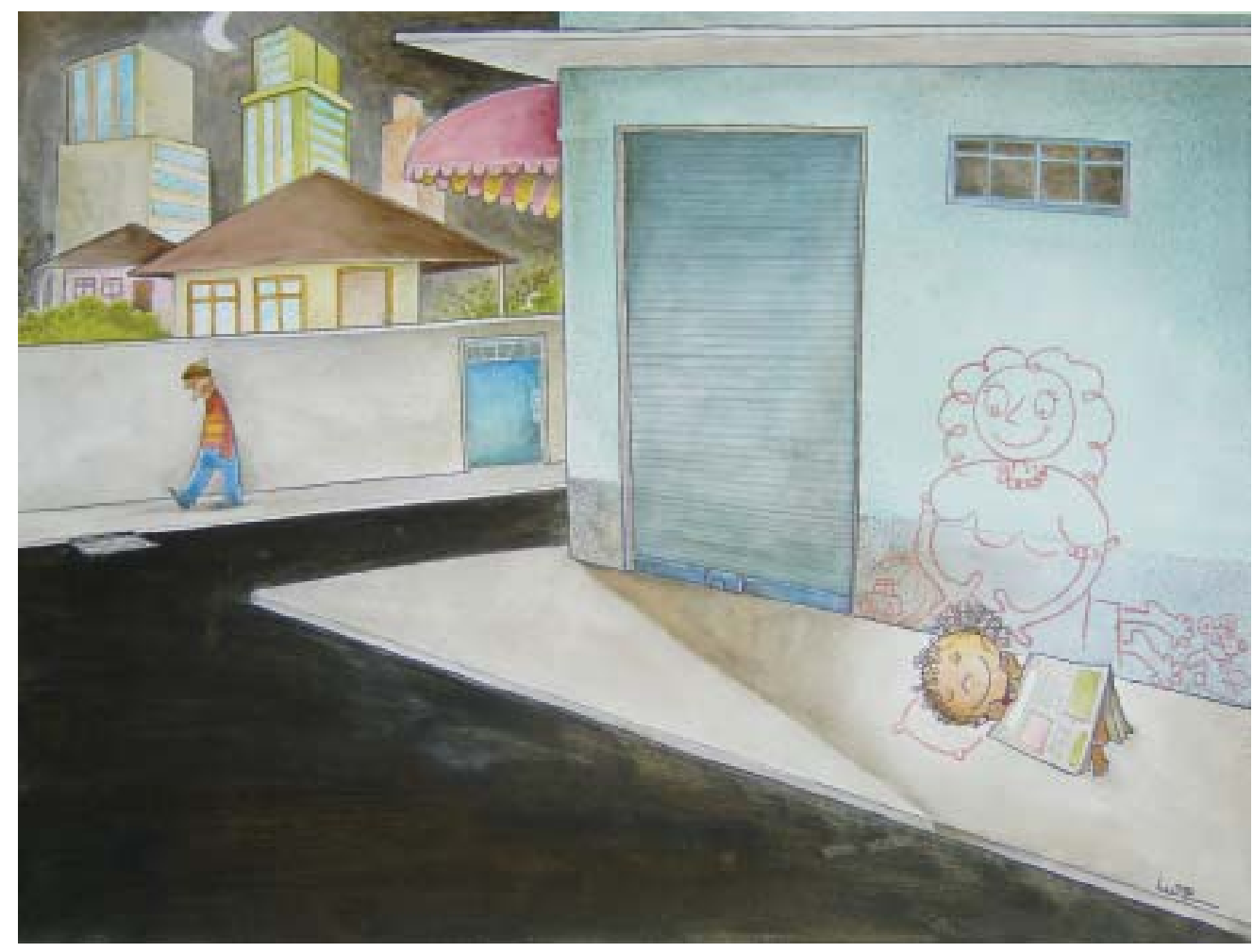

Figura 2 - Cartum sobre miséria e crianças de rua

A imagem acima (Figura 2$)^{8}$ pode ser considerada um cartum. ${ }^{9}$ A situação retratada nesse cartum evidencia o problema da miséria e das crianças de rua, presente em diferentes sociedades urbanas em todo o mundo. O cartunista propõe a mensagem em apenas um quadro, constituído somente de texto icônico. No entanto, podemos perceber dois planos distintos: um plano mais próximo do leitor - o da criança (de rua); e outro plano mais distante, mas não menos importante, aquele do adulto (pedestre). Pela inferência da seqüência de ações, podemos supor que a criança, que segura o lápis na mão, e que dorme na calçada, desenhou uns traços de mãe (mulher adulta) que a teria no colo. Junto à mãe, podemos ver também o desenho de um provável uso de pelúcia e outros brinquedos, o que nos levaria a pensar (e à criança, principalmente!) em um quarto, um lar.

\footnotetext{
Essas linguagens estão previstas nos PCN de Língua Portuguesa da Educação Básica como veremos adiante.

8 Cartum feito especialmente para o XVII Salão Carioca de Humor, onde ganhou o segundo prêmio.

9 Também de autoria de Lute (veja-se nota anterior).
} 
Como elementos referenciais para a compreensão da mensagem, vemos um jovem, uma bandana na testa, calças largas, mãos nos bolsos. No momento que os grafiteiros costumam agir (madrugada - rua vazia, lua, noite escura, cenário urbano), a criança que dorme na calçada sorri: ela parece receber o carinho da mãe imaginária/ imaginada. Através do sorriso da criança, sentimos o incômodo refletido no adulto indiferente à cena em primeiro plano - estratégias discursivas articuladas pelo cartunista em busca do efeito no leitor - um efeito de crítica, de denúncia social.

\section{"Um desenbo que pensa" (ou que faz pensar)}

$\mathrm{Na}$ leitura de charges e cartuns, atuam juntamente às estratégias discursivas para a produção do efeito de sentido que se pretende nesse gênero jornalístico e o contrato de comunicação midiática proposto por Charaudeau (2005, 2006).

Quanto ao contrato de comunicação, Charaudeau o compreende como um tipo de acordo prévio entre os interlocutores a partir de dados de um quadro de referência de uma determinada situação de comunicação. "A situação de comunicação é como uma cena de teatro, com suas limitações de espaço, de tempo, de relações, de falas, sobre a qual se realiza a peça das trocas sociais e o que lhes confere o valor simbólico"10 (CHARAUDEAU, 2005, 2006). Segundo esse autor, o contrato de comunicação é um contrato de reconhecimento das condições de realização do tipo de troca linguageira na qual os interlocutores estão engajados e resulta das características próprias à situação de troca.

Previstos, assim, os papéis de humorista e de leitor do jornal, é possível compreender o espaço do Humor Gráfico na imprensa. Nessa perspectiva, a charge surge como "comentário" da notícia, e é publicada, normalmente, junto a outros textos mais formais de comentário: o editorial, o artigo de opinião, a coluna, a tribuna.

$\mathrm{Na}$ visão de Charaudeau, comentar um acontecimento "constitui uma atividade discursiva, complementar ao relato, que consiste em exercer suas faculdades de raciocínio para analisar o porquê e o como dos seres que se acham no mundo e dos fatos que aí se produzem" (CHARAUDEAU, 2006, p. 175). Na charge, comentar a notícia, o acontecimento relatado, é criticá-lo. "O comentário $[\ldots]$ não se contenta em mostrar ou imaginar o que foi, o que é ou o que se produz; o comentário procura revelar o que não se vê, o que é latente [...]"(CHARAUDEAU, 2006, p. 175).

Nesse caso, o leitor é chamado a se divertir, a rir o riso adjetivado que a situação relatada conduz, a rir de si mesmo, quando não lhe resta outra alternativa... Mas, a charge não instiga apenas ao riso, instiga também a uma decisão: “o comentário [...] põe o leitor em questão - exige uma atividade intelectiva, um trabalho de raciocínio, uma tomada de posição contra ou a favor, e desta atividade não há ninguém, no fim da troca, que saia incólume (o comentário é histérico)." (CHARAUDEAU, 2006, p. 175).

Ainda de acordo com Charaudeau, na encenação midiática do comentário, o comentador deve seguir modos de raciocínio simples e motivadores. A esse respeito, a charge é campo fértil: os argumentos se baseiam em crenças, "que são amplamente compartilhadas pelo grande público, sendo, pois, suscetíveis de atingi-lo com mais eficiência [...] e os lugares-comuns, que facilitam a compreensão do público" (CHARAUDEAU, 2006, p. 176), além de "um efeito de dramatização", o exagero e a sátira, permitido pelo contrato de comunicação midiática, como vimos anteriormente, ao humor gráfico.

Esse exagero nos remete ao discurso da loucura, segundo a abordagem de Foucault (1971, 1996). A charge é "a palavra do louco", palavra que lhe é dada simbolicamente e a qual se atribui "estranhos poderes, o de dizer uma verdade escondida" (FOUCAULT, 1996, p. 11). Por ser "loucura", em oposição à razão dos jornalistas sérios das colunas e dos editoriais, à charge é permitido dizer o que talvez nunca é dito.

Dessa forma, acreditamos que o discurso do humor gráfico se mostra favorável a uma educação crítica da leitura da mídia, na medida em que fala de ditos e de não-ditos de forma lúdica.

10 Tradução nossa. 


\section{Humor gráfico na escola - a educaçấo do olbar e da escuta}

Em uma sociedade imagética como a nossa, a educação do olhar se faz imprescindível. Um dos lugares privilegiados para a educação do olhar é a escola. E o que vem a ser uma educação do olhar? "Essa é uma maneira de ler o mundo. Uma maneira importante, que traz informação, troca, que alarga horizontes e permite a constante ampliação dos níveis de consciência humana" (FURNARI, 2002). A educação do olhar, dessa forma, propõe uma perspectiva crítica de leitura por trás da imagem, o que dizemos, para a leitura da palavra, saber ler nas entrelinhas. Mas, não é apenas isso. Na percepção do jornalista e pesquisador Bruno Leal (1996), a idéia do Outro é condição necessária à educação do olhar. Segundo ele:

Ao trazer para a sala de aula algo que já faz parte do cotidiano das pessoas, o professor tem, dessa forma, condições de educá-las nessa outra linguagem. A educação para a imagem, nesse caso, passa necessariamente pelo reconhecimento da alteridade, isto é, da diferença de olhar implícita a ela. Afinal, a imagem que o espectador [leitor] recebe é sempre de um outro: de um outro eu, num outro tempo ou espaço, de um outro lugar, de outra cultura, de outras pessoas. Assim, trabalhar a alteridade implícita à imagem significa trabalhar as diferenças existentes na sociedade e no mundo [...] Ver alguma coisa através da TV [ou do impresso] é ver como alguém viu alguma coisa. (LEAL, 1996, p. 23).

Assim, de acordo com os Parâmetros Curriculares Nacionais, que orientam o trabalho pedagógico da educação básica, alguns dos elementos do trabalho com a leitura de imagens como charges e cartuns favorecem aspectos importantes da formação: discutir sobre a imagem permite a compreensão das especificidades de diferentes linguagens, a socialização de opiniões e o confronto de diferentes pontos de visa, desenvolvimento da autonomia moral e intelectual. ${ }^{11}$ Paralelamente à educação do olhar, proporciona-se à educação da escuta atenta, ativa e participativa.

Desse modo, a educação da/pela imagem e pela oralidade permite o desenvolvimento da leitura e da expressão também da/pela palavra: cognitivamente, o sujeito aprendiz se apropria da autoria - a expressão de suas idéias alcança também o âmbito da escrita.

A escola não trabalha o ser, o constituir-se leitor e escritor. Espera que as crianças se tornem leitoras e escritoras como resultado de seu ensino. No entanto, a própria prática escolar é a negação da leitura e da escritura como prática dialógica, discursiva, significativa [...] Primeiro, ou concomitantemente, ela [a criança] precisa ocupar o espaço como protagonista, interlocutora, como alguém que fala e assume o seu dizer. (SMOLKA, 1996, p. 93).

\section{Letramento e formação de professores}

A educação para a mídia se inscreve na necessidade da ação do professor e, mais do que isso, na formação do professor em seu próprio processo de autonomia e autoria. Nessa perspectiva, concordam Zanchetta Jr. (2005) e Kleiman (2006); o primeiro, na perspectiva direta da educação para a mídia; a segunda, na perspectiva da formação dos professores, de forma específica.

Para Zanchetta Jr., deve-se problematizar a participação da escola na questão da mídia. Segundo o autor, "há discursos prontos que entram para dentro da escola, mas a escola não tem discurso para dialogar com esses" e isso se deve à ausência de formação do professor para o discurso midiático. $\mathrm{Na}$ sua opinião, é necessário desenvolver nos professores uma "memória de informação jornalística", na sua própria formação e na sua prática pedagógica, através do estímulo da participação política, a voz da coletividade, inserida, por sua vez, na própria mídia.

11 "Utilizar diferentes linguagens - verbal, musical, matemática, gráfica, plástica e corporal - como meio para produzir, expressar e comunicar suas idéias, interpretar e usufruir das produções culturais, em contextos públicos e privados, tendendo a diferentes intenções e situações de comunicação " (Parâmetros Curriculares Nacionais, Objetivos gerais, 1998, p. 7). "Ao se pensar em um trabalho que valorize o diálogo como estratégia de aprendizagem é importante que se promova o debate de opiniões, a formulação de situações-problema, que se analisem as hipóteses levantadas, as opiniões diferentes. A socialização das opiniões e o confronto de diferentes posicionamentos sobre os assuntos mais variados contribuirão para a construção do saber por meio de múltiplas visões. Desta forma, o diálogo partirá da pluralidade de idéias rumo à construção do conhecimento, contribuindo para a conquista da autonomia moral e intelectual dos alunos " (Parâmetros Curriculares Nacionais, 1998 - Apresentação dos temas transversais, p.109). 
Nesse caminho, acredita Kleiman na idéia do professor como agente de letramento, ${ }^{12}$ responsável pela inserção dos alunos nas práticas sociais $^{13}$ de leitura e de escrita em contexto escolar. De acordo com essa concepção, um agente de letramento é um agente social ${ }^{14}$ e, como tal, é conhecedor dos meios, fraquezas e forças dos membros do grupo e de suas práticas locais, mobilizador de seus saberes e experiências, seus "modos de fazer" (inclusive o uso das lideranças dentro do grupo), para realizar as atividades visadas: ir e vir, localizar, arrecadar, brincar, jogar, pesquisar (KLEIMAN, 2006). Dessa forma, "ao mobilizar as capacidades dos membros do grupo, ao favorecer a participação de todos segundo suas capacidades, o agente de letramento, ele próprio um ator social, cria as condições necessárias para a emergência de diversos atores"(KLEIMAN, 2006). Isso asseguraria, segundo a autora, uma mudança de papéis tradicionalmente institucionalizados entre professor e aluno, e conseqüentemente, uma mudança de processos de construção do conhecimento. "Daí a necessidade de oferecer aos professores cursos que promovam representações orientadas para a participação coletiva, para a mobilização e agência, para a autonomia e autoria”, salienta Kleiman.

\section{Considerações finais}

Como vimos, a construção em um processo educativo de um "bom leitor de mídia" é uma necessidade de nosso tempo - a sociedade da informação em que vivemos exige uma educação cada vez mais pautada em seus instrumentos - os meios de comunicação - para a efetiva construção da cidadania e do contínuo aprimoramento da democracia.

A formação de professores para uma leitura eficaz que busque identificar estratégias textuaisdiscursivas no discurso informativo está no foco, ao nosso ver, de uma educação para a mídia realmente efetiva e que deveria, também em nossa opinião, constituir os temas transversais propostos nos Parâmetros Curriculares Nacionais. Conhecer os elementos de referenciação e as condições de inferenciação propostos na situação de comunicação com a qual se lida; conhecer as condições de formação de determinados discursos no âmbito das instituições que o produzem e no âmbito das instâncias que o recebem, é mais do que ler nas entrelinhas, interpretar e compreender, concernentes às competências leitora e produtora de texto no contexto escolar. Isso diz respeito, em um sentido mais abrangente, à leitura de mundo e à construção da autoria do sujeito em formação para a cidadania.

Nesse sentido, a proposta do Projeto de Extensão Jornal, Leitura e Escola busca levar sua contribuição através do letramento midiático. A formação do professor da Educação Básica como agente de letramento midiático através do projeto evidencia, como resultados alcançados até então, o favorecimento da construção de um "olhar" crítico para as mídias em geral, especificamente, para a leitura do jornal impresso e do texto jornalístico noticioso como referência dessa discussão.

Para tanto, continuamos nos guiando através de algumas questões que norteiam a proposta: em que medida professores e alunos da educação básica dominam o discurso midiático e suas especificidades ao abordarem a leitura de mídias na escola? Como se articulam as noções de verdade, fato, versão e opinião no tratamento de textos jornalísticos em sala de aula? Como estão sendo abordados os pressupostos necessários para uma leitura, compreensão e interpretação crítica do texto noticioso jornalístico a partir das condições de produção, recepção e circulação desses textos nas escolas?

Nesse diálogo entre comunicação e educação, a preparação de estudantes universitários de jornalismo para o trabalho em colaboração com a formação de educadores para o discurso midiático tem se mostrado muito pertinente também em relação à própria formação do futuro jornalista, que desenvolve aspectos da ética imprescindíveis, a nosso ver, à construção da democracia que

12 Considerando letramento um conjunto de crenças, experiências e saberes dos usuários da língua nos diversos contextos de uso, Kleiman (2006) propõe a concepção de um novo papel para o professor, capaz de atuar em novos contextos, reestruturados segundo novas concepções de usos da língua escrita e das funções da escola no ensino desses usos. Segundo a autora, o professor como agente de letramento substituiria ou mesmo complementaria a idéia de mediador, que outorga um papel central ao professor na co-construção do saber.

13 “[...] entendemos uma seqüência de atividades recorrentes e com um objetivo comum que dependem de tecnologias, de sistemas de conhecimento específicos e de capacidades para a ação " (KLEIMAN, 2006).

14 "Um agente social é um mobilizador, dos sistemas de conhecimento pertinentes, dos recursos, das capacidades dos membros da comunidade: no caso da escola, seria um promotor das capacidades e recursos de seus alunos e suas redes comunicativas para que participem das práticas sociais de letramento, as práticas de uso da escrita situadas, das diversas instituições” (KLEIMAN, 2006). 
queremos. Isso se constitui em um verdadeira interação entre universidade e comunidade, em que ambos se beneficiam.

Letramento midiático consiste, portanto, em saber lidar com ação da informação nas práticas sociais que a constroem, não apenas pensar em novas linguagens do texto e dos meios ou nas condições de produção e recepção dos discursos, mas é também uma questão de posicionamento interativo, cognitivo, lingüístico, político e social do sujeito, com vistas em seu processo de autor e ator, contribuindo na transformação de si mesmo e do outro.

Concluímos, até aqui nesse processo, que a educação para a mídia ainda é uma questão pouco enfatizada e debatida na sociedade. Percebe-se a urgência dessa discussão relevando a necessidade de parcerias interdisciplinares no processo de formação do cidadão como um todo, capacitando aluno e professor em competências e habilidades necessárias à construção da democracia no país através de uma leitura critica da mídia, e envolvendo, prioritariamente, os profissionais da comunicação nessa discussão.

\section{Referências}

ASSIS, Juliana Alves. Explicitação/implicitação no $e$-mail e na mensagem em secretária eletrônica: contribuições para o estudo das relações oralidade escrita. 2002. 281 f. Tese (Doutorado em Lingüística) - Faculdade de Letras, Universidade Federal de Minas Gerais, Belo Horizonte, 2002.

BAKHTIN, M. Estética da criação verbal. São Paulo: Martins Fontes, 2000.

BERGSON, Henri. O riso: ensaio sobre a significação do cômico. 3. ed. Rio de Janeiro: Zahar, 1980.

BRASIL. Secretaria de Educação Fundamental. Parâmetros curriculares nacionais/Secretaria de Educação Fundamental. Brasília: MEC /SEF, 1998.

CASTRO, Maria Lídia Dias de. A dialogia e os efeitos de sentido irônicos. In: BRAIT, BETH (Org.). Bakhtin, dialogismo e construção do sentido. Campinas, São Paulo: Editora da UNICAMP, 1997.p. 129-137.

CHARAUDEAU, Patrick. Les médias et l'information: l'impossible transparence du discours. Bruxelles: De Boeck Université, 2005.
Contexto, 2006.

Discurso das mídias. São Paulo:

COLOMBO, Sylvia. Humoristas estão muito certinhos. Folha de S. Paulo, São Paulo, 13 mar. 2007. Ilustrada, p. E1.

DINIZ, L. et al. Olhar crítico sobre a leitura dos jornais. Hoje em Dia, Belo Horizonte, 6 jan. 2006. Minas/Uni-BH, p. 20.

DOLABELlA, Ana Rosa Vidigal. O discurso relatado na imprensa brasileira: jogo de estratégias de apropriação de vozes e de construção de efeitos. 1999. 378 f. Dissertação (Mestrado em Lingüística) - Faculdade de Letras, Universidade Federal de Minas Gerais, Belo Horizonte, 1999.

DOLABELLA, Ana Rosa Vidigal. Propostas de trabalho com o livro A linha de Mário Vale. Separata de: VALE, Mário. A Linha de Mário Vale. Belo Horizonte: RHJ, 2006a. 9 p.

DOLABELLA, Ana Rosa Vidigal. Referenciação e letramento midiático. In: SEMINÁRIO NACIONAL O PROFESSOR E A LEITURA DO JORNAL - O jornal na Educação: dos entretantos aos finalmentes, 3., 2006b, Campinas, São Paulo. Anais... Campinas: Unicamp, 2006b. 1 CD-ROM.

FOUCAULT, M. A ordem do discurso. São Paulo: Loyola, 1971. . São Paulo: Loyola, 1996.

FURNARI, Eva. As imagens nas paredes da escola. Leitura e Imagem, 2002. Disponível em: <http:/ / www.tvebrasil.com.br/SALTO/boletins2002/lii/ lii0.htm>. Acesso em: 10 ago.2006.

KLEIMAN, Ângela B. Processos identitários na formação profissional - o professor como agente de letramento. In: CORREAA, Manoel (Org.). Ensino de língua: letramento e representações. Campinas: Mercado de Letras, 2006.p. 75-91.

$\mathrm{KOCH}$, Ingedore. Referenciação e orientação argumentativa. In: KOCH, I. V.; MORATO, E.M; BENTES, A. C. (Org.). Referenciação e discurso. São Paulo: Contexto, 2005. p. 33-52.

LEAL, Bruno. O desafio da imagem. Revista Presença Pedagógica, Belo Horizonte, v. 2, n. 7, jan./ fev. 1996. p. 15-25.

MOUILLAUD, Maurice; PORTO, Sérgio Dayrell (Org.). O Jornal, da forma ao sentido. Brasília: Paralelo 15, 1997. 
RIANI-COSTA, Camilo Floriano. Linguagem e cartum... Ta rindo do quê? In: XXV CONGRESSO BRASILEIRO DE CIÊNCIAS DA COMUNICAÇÃO, 25., 2002, Salvador. Anais... Salvador: INTERCOM, 2002.

RODRIGUES, Adriano Duarte. O acontecimento. In: TRAQUINA, Nelson (Org.). Jornalismo: questões, teorias e estórias. 2. ed. Lisboa: Veja, 1999.

ROMUALDO, Edson Carlos. Charge jornalística: intertextualidade e polifonia - um estudo de charges da Folha de S. Paulo. Maringá: EDUEM, 2000.

SANTOS, Lunarde Teles dos. Re: Imagens [mensagem pessoal]; Re: Artigo. Mensagem recebida por arosavidigal@terra.com.brem 29 nov 2006; por anarosavidigal@gmail.com em 23 ago 2007.
SMOLKA, Ana Luiza Bustamante. A criança na fase inicial da escrita: a alfabetização como processo discursivo. 7. ed. São Paulo: Cortez, 1996.

VALE, Mário. Linha direta com o Mário. Propostas de trabalho com o livro A linha de Mário Vale. Separata de: VALE, Mário. A linha de Mário Vale. Belo Horizonte: RHJ, 2006. p. 6-8.

ZANCHETTA Jr., Juvenal. Challenges of approaching the press at school. Educ. Soc., Campinas, v. 26, n. 93, 2005 . Disponível em: <http://www.scielo.br/scielo.php?script=sci_arttext\&pid $=$ S0101-733020050$00400021 \& \operatorname{lng}=$ en\&nrm=iso $>$. Acesso em: fev. 2007.

Recebido em: 04/02/2007

Received in: 02/04/2007

Aceito em: 26/03/2007

Accepted in: 03/06/2007 